Check for updates

Cite this: Phys. Chem. Chem. Phys. 2020, 22, 25492

Received 22nd August 2020, Accepted 2nd November 2020 DOI: $10.1039 / \mathrm{d} 0 \mathrm{cp} 04451 \mathrm{~b}$ rsc.li/pccp

\title{
Increasing the weights in the molecular work-out of cis- and trans-formic acid: extension of the vibrational database via deuteration $\dagger$
}

\author{
Arman Nejad, (D) Martin A. Suhm (D) and Katharina A. E. Meyer (D)*
}

\begin{abstract}
The higher-energy cis- as well as the global minimum trans-rotamers of the four H/D isotopologues of the formic acid monomer have been examined with Raman jet spectroscopy extending the vibrational gas phase reference database by eleven new cis-band positions for HCOOD, DCOOH, and DCOOD. With these new additions, all $\mathrm{O}-\mathrm{H} / \mathrm{D}, \mathrm{C}-\mathrm{H} / \mathrm{D}$, and $\mathrm{C}=\mathrm{O}$ stretching as well as the $\mathrm{O}-\mathrm{D}$ in-plane bending vibrations of these higher-energy rotamers are known in addition to the previously determined $\mathrm{C}-\mathrm{O}$ stretch and $\mathrm{OH}$ torsion of cis- $\mathrm{HCOOH}$. Further, a comparison of the vibrational spectra of all four $H / D$ isotopologues of the globally stable trans-rotamer of formic acid is shown to be very helpful in revealing similarities and differences in these systems, particularly with regard to Fermi resonances. Amongst the most prominent ones is the $\nu_{5} / 2 \nu_{9}$ resonance doublet of trans $-\mathrm{HCOOH}$, for which we provide more insight into a recently suggested label switch of the resonance partners via the comparison of infrared and Raman jet spectra.
\end{abstract}

\section{Introduction}

As an important contributor to atmospheric chemistry, ${ }^{1,2}$ the formic acid monomer, particularly its global minimum trans-conformation, has received much attention over the years both from the experimental ${ }^{3-10}$ as well as the theoretical ${ }^{11-13}$ side. Despite the low abundance of merely $0.1 \%$ at room temperature, the first gas phase detection of the higherenergy cis-conformer was achieved with microwave spectroscopy in 1976 by Hocking, ${ }^{14}$ enabled by the threefold larger dipole moment of cis- $(3.79 \mathrm{D})$ compared to trans-HCOOH $(1.42 \mathrm{D}) .^{15}$ The first vibrational characterisation of $c i$-formic acid was accomplished in 1997 for $\mathrm{HCOOH}$ in an argon matrix via $\mathrm{OH}$ overtone excitation from the global minimum transrotamer ${ }^{16}$ and was subsequently extended to $\mathrm{DCOOH}^{17}$ and HCOOD. ${ }^{18,19}$ For a direct comparison to theory, ${ }^{20}$ however, these values are not so practical, as the host-guest interaction needs to be captured on the theoretical side which can be challenging, as recently shown by Ito for the formic acid dimer. ${ }^{21}$ The first and until 2018 only cis-formic acid fundamental measured in the gas phase was the $\mathrm{OH}$ torsion connecting both minima ${ }^{22}$ - the vibrational mode with the largest

Institute of Physical Chemistry, University of Göttingen, Tammannstr. 6, 37077 Göttingen, Germany. E-mail: katharina.meyer@chemie.uni-goettingen.de $\dagger$ Electronic supplementary information (ESI) available: cis-Formic acid spectra, comparison of formic acid vibrational nomenclature, harmonic avoided crossing calculated at other levels than B3LYP-D3, as well as computational raw data and further experimental details. See DOI: 10.1039/d0cp04451b (predicted) spectral separation between both conformers. Four new band positions of cis- $\mathrm{HCOOH}$ have been determined in 2018 and 2019 with Raman jet spectroscopy, utilising thermal excitation to increase the cis-formic acid abundance by an order of magnitude ${ }^{23,24}$ prior to the expansion. Here, we present the first perturbation-free band positions of partially and fully deuterated cis-formic acid, extending the available cis-database by more than $200 \%$ from five to sixteen fundamentals. In 2019, cis-formic acid has also been detected as a distinct species in solution, ${ }^{25}$ where it has a much higher abundance than in the gas phase. The O-D and $\mathrm{C}=\mathrm{O}$ stretches were shown to be higher in frequency than those in the trans-form, as observed here under vacuum isolation, but only in weakly hydrogen-bonded solvents. In water, the sequence inverts for the O-D stretch, underscoring the importance of reliable reference values in the gas phase for theory.

Despite the completion of the vibrational gas phase database for the trans-rotamers of the H/D isotopologues of formic acid (with the exception of $\nu_{8}$ of HCOOD), there is still ambiguity in the assignment of Fermi resonance pairs. One prominent example is the $\nu_{5} / 2 \nu_{9}$ Fermi resonance of trans- $\mathrm{HCOOH}$. This resonance is part of a larger resonance polyad involving half a dozen of states ${ }^{26}$ and problems with the $\nu_{5}$ assignment were noted early on. In 2019, Hull et al. presented convincing experimental evidence that the overtone $2 \nu_{9}$ is - contrary to previous beliefs - lower in energy than the fundamental $\nu_{5},{ }^{27}$ in agreement with recent high-level calculations. ${ }^{11,12}$

As we will highlight in this contribution, one of the most crucial and insightful aspects that improves our understanding 
of near-degeneracies in these systems is the comparison of vibrational spectra of all four H/D isotopologues. The work of Redington, who has analysed 24 isotopologues of the formic acid monomer in a neon matrix, ${ }^{28}$ is an impressive example of such rigorous comparison. Further, we showcase the indispensability of Raman spectroscopy for a thorough vibrational characterisation of the formic acid monomer, which is so far underrepresented $^{4,5,23,24,29-31}$ in comparison to a wealth of infrared studies (see for example ref. 3, 6-10, 32-41 and references therein). We extend and update the significant Raman gas phase work on hydrogenated and deuterated formic acid by Bertie et al., ${ }^{4,5}$ which was focussed on the characterisation of the dimer.

From a computational point of view, the small size of only five atoms and two conformational isomers (energy difference of 16.3(4) $\mathrm{kJ} \mathrm{mol}^{-1}$ (ref. 14)) makes the formic acid monomer particularly suitable for benchmarking quantum chemical models. The availability of benchmarking data in higher-energy regimes of the potential energy hypersurface (PES), e.g., local minima, is especially important, as it enables the assessment of the globality of the PES description. The need for higher-energy reference data is illustrated by two recent high-level variational anharmonic calculations, namely vibrational configuration interaction (VCI ${ }^{11}$ and multi-configuration time-dependent Hartree (MCTDH) ${ }^{12}$ where the mean absolute deviation (MAD) between both models is $4 \mathrm{~cm}^{-1}$ for the global minimum trans-, but nearly three times as large $\left(12 \mathrm{~cm}^{-1}\right)$ for the cis-conformer. For trans$\mathrm{HCOOH}$, all nine fundamentals were considered for this analysis, but for the higher-energy cis-rotamer only eight, as $\nu_{1}$ was not reported in ref. 11. Another excellent test to reveal weaknesses in theoretical models are near-degeneracies, as recently showcased for the glycolic acid monomer, ${ }^{42}$ and extended in this work to the trans-rotamer of the formic acid monomer. A full characterisation of the rotational and vibrational states of cis- and trans-formic acid, which contribute to their partition function, together with an independent experimental value of the equilibrium constant between the two species could provide a more accurate experimental value for the energy difference between the two species, ${ }^{43}$ which so far relies on a single microwave analysis. ${ }^{14}$

\section{Experimental and computational methods}

The Raman jet set-up used to record all spectra has been described in detail before. ${ }^{24,44,45}$ Briefly, formic acid was seeded into helium and expanded at different temperatures through a vertical slit nozzle at 0.5 bar into an evacuated jet chamber (background pressures of 1-2 mbar during the expansion). Before the expansion, the acid-in-helium mixture was further diluted with helium yielding acid concentrations of $<0.2-0.4 \%$ (Table S1 in the ESI $\dagger$ ). Both the nozzle and its feed-line are heatable, which can be exploited to enhance the relative population of higher-energy conformers before the expansion, ${ }^{24}$ while cluster formation is suppressed. To ensure stable conditions during the long exposures needed for the low spontaneous Raman scattering photon flux, the gas expansion is continuous (see ref. 45 for further details). A $25 \mathrm{~W}$ continuous-wave Spectra Physics Millennia eV $532 \mathrm{~nm}$ laser was used to probe the expansion. For the HCOOD measurements, a slightly lower laser power of $24 \mathrm{~W}$ was employed. The distance between the slit nozzle and the laser beam was set to $1 \mathrm{~mm}$. The scattered light was collected perpendicular to the laser and to the nozzle flow via a camera lens and focussed onto a $1 \mathrm{~m}$ monochromator (McPherson) which disperses the photons onto 1340 pixel columns of a $1340 \times 400$ liquid nitrogen-cooled CCD-camera (Princeton Instruments, PyLoN 400B), that was operated in vertical binning mode (400 pixels). The combination of laser and monochromator results in a resolution of about 1.5-2.0 $\mathrm{cm}^{-1}$, depending on the spectral range. Therefore, we generously assign band centre errors of $\pm 2 \mathrm{~cm}^{-1}$. Exposure times of 200-300 s were used per scan and typically 5-9 scans were co-added for each spectral window. To calibrate the raw spectra in the wavenumber domain, neon lines were measured and compared to the known vacuum transitions in the NIST database. Spikes due to cosmic rays were eliminated by comparing multiple exposures for the same pixel column.

The FTIR jet spectra were recorded with a Bruker IFS $66 \mathrm{v}$ spectrometer equipped with a globar, a potassium bromide beam splitter, and potassium bromide optics. The modulated IR beam is gently focussed on the pulsed jet expansion from a $600 \times 0.2 \mathrm{~mm}^{2}$ slit nozzle. Behind it, the beam is focussed onto a mercury cadmium telluride (MCT) detector. A comparison of the expansion conditions of the FTIR and Raman set-up can be found in ref. 46 and further details on the FTIR set-up in ref. 47.

Geometry optimisations and the calculation of harmonic vibrational frequencies, IR intensities, and Raman activities have been performed with Gaussian 09 Rev. E.01. ${ }^{48}$ Keyword specifications for all calculations are summarised in the ESI $\dagger$ (Table S2). From the computed Raman activity $A_{i}$, the Raman scattering cross-section $\sigma_{i}$ was calculated as

$$
\sigma_{i}=\frac{2 \pi^{2} h}{45 c \omega_{i}} \cdot \frac{\tilde{\nu}_{\text {Laser }}\left(\tilde{\nu}_{\text {Laser }}-\omega_{i}\right)^{3}}{1-\exp \left(-\frac{h c \omega_{i}}{k_{\mathrm{B}} T_{\mathrm{vib}}}\right)} \cdot g_{i} A_{i},
$$

where $\tilde{\nu}_{\text {Laser }}=(532 \mathrm{~nm})^{-1}$ is the laser wavenumber, $T_{\text {vib }}$ the vibrational temperature, $\omega_{i}$ the harmonic wavenumber, $g_{i}$ the degeneracy of the vibration, and $c$ the speed of light in vacuum. To roughly match the vibrational temperature in our jet, a temperature of $100 \mathrm{~K}$ was assumed in all our calculations.

For spectral assignments, the B3LYP functional ${ }^{49,50}$ was employed using two-body dispersion corrections (D3), ${ }^{51}$ Becke-Johnson damping, ${ }^{52}$ and the aug-cc-pVTZ basis set, ${ }^{53}$ hereafter denoted as aVTZ. All harmonic vibrational frequencies were scaled to the respective trans-formic acid band in each spectral window and in case of Fermi resonances, to the resonance centre ascertained from the overall scattering intensity. A list of the calculated harmonic vibrational frequencies, IR intensities, and Raman scattering cross-sections can be found in Table S3 in the ESI. $\dagger$ 
In order to analyse harmonic mode mixing (see Section 3.3), additional harmonic vibrational frequency calculations were carried out at the PBE0-D3(BJ), ${ }^{54}$ B2PLYP-D3(BJ), ${ }^{55} \mathrm{HF}, \mathrm{MP} 2^{56}$ (all Gaussian 09 Rev. E.01 ${ }^{48}$ ), and $\operatorname{CCSD}(\mathrm{T})^{57}$ levels (CFour version $1^{58,59}$ ).

\section{Results and discussion}

\section{1 cis-Formic acid fundamentals}

To detect the cis-conformers of DCOOH, HCOOD, and DCOOD, Raman jet spectroscopy has been exploited in combination with thermal excitation between 100 and $190{ }^{\circ} \mathrm{C}$ utilising a heatable nozzle and feed-line, followed by a supersonic expansion to rapidly freeze out the enhanced cis-population ${ }^{24}$ of up to $1-2 \%$. This technique is a variant of earlier trapping methods ${ }^{60}$ with the advantage that the trapped species are generated in a state which is easily accessible to quantum chemical modelling. By intensity-scaling the spectra of a temperature series to the respective trans-fundamental in each spectral region, cis-formic acid bands and non-isomeric hot bands, i.e., transitions from thermally populated states localised in trans-formic acid, can be easily distinguished from cold monomer and cluster bands, as they increase in intensity with temperature, whereas the cluster bands decrease. An illustrative example of this can be seen in the $\nu_{2}$ spectra of $\mathrm{HCOOH}$ in Fig. S3 in the ESI. $\dagger$

There are two measures to identify the molecular origin of a hot band - the band position difference to the trans-fundamental and the intensity. In the perturbational picture, ${ }^{61}$ the spectral shift between a fundamental $\nu_{i}$ and the hot band $\nu_{i}+\nu_{j}-\nu_{j}$ amounts to the anharmonic matrix element $x_{i j}\left(2 x_{i i}\right.$ for $\left.2 \nu_{i}-\nu_{i}\right)$, which mediates binary coupling between two vibrational modes $i$ and $j$ (diagonal anharmonicity along mode $i$ ). The intensity of a nonisomeric hot band can be estimated from the expected Boltzmann population of that low-lying energy level $j$ assuming similar Raman scattering cross-sections (see ref. 24 for further details). In case of an isomeric hot band, the expected population can be estimated from the energy difference between both conformers $\left(1-2 \%\right.$ at $\left.190{ }^{\circ} \mathrm{C}^{24}\right)$ and the difference in band position corresponds to the cis-trans-shift.

Fig. 1 shows the normalised relative Raman scattering crosssections for all four H/D isotopologues and both rotamers of formic acid, indicating which vibrations are accessible with our experimental approach. For reasons of simplification and unification, we employ the Herzberg nomenclature of $\mathrm{HCOOH}$ for all isotopologues and rotamers (see Table S4 in the ESI $\dagger$ for comparison).

As for $\mathrm{HCOOH},{ }^{24}$ the most Raman active modes of the deuterated isotopologues are the $\mathrm{O}-\mathrm{H} / \mathrm{D}, \mathrm{C}-\mathrm{H} / \mathrm{D}$, and $\mathrm{C}=\mathrm{O}$ stretches $\left(\nu_{1}-\nu_{3}\right)$, for which all missing cis-fundamentals were determined in this work. We note that the assignment of $\nu_{2}$ of cis-DCOOH is somewhat tentative due to the prominent rovibrational and hot band structure of the respective trans-band (cf. Fig. S3 in the ESI $\dagger$ ). The same applies to $\nu_{6}$ of $c i s$-HCOOH. ${ }^{62}$ Due to the abundance disadvantage of cis-formic acid, most of the remaining cis-fundamentals are more difficult to access with our experimental approach. The notable exception is the O-D in-plane bending vibration $\nu_{5}$ of HCOOD and DCOOD. For other cis-fundamentals with seemingly high intensity such as $\nu_{4}$ and $\nu_{6}$ of DCOOH ( $c f$. Fig. 1), spectral congestion due to an excessive hot band structure currently limits further conclusions. Guidance from theory would be particularly helpful for these spectral regions. $\nu_{8}$ and $\nu_{9}$ are close to the detection limit for the trans-rotamer, and below it for the cis-rotamer impurity.

A list of all available hydrogenated and newly determined deuterated (perturbation-free) cis-fundamentals of the formic

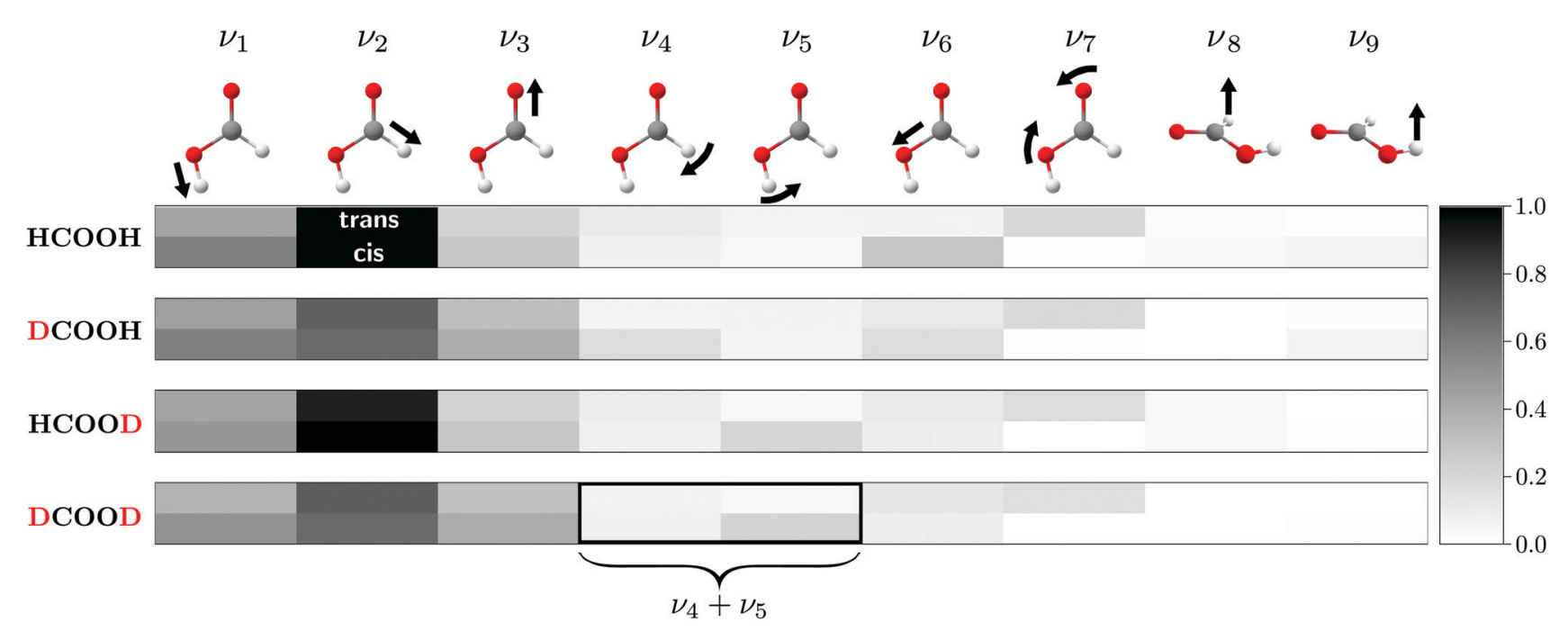

Fig. 1 Harmonic (B3LYP-D3(BJ)/aVTZ) Raman scattering cross-sections of the formic acid monomer for both rotamers of all four H/D isotopologues, normalised to $\nu_{2}$ of HCOOD (scaling factor $175.9 \times 10^{-36} \mathrm{~m}^{2} \mathrm{sr}^{-1}$ ). A darker grey tone for the cis-rotamer indicates higher visibility than for the transrotamer, but the lower cis-abundance in the experiment must be kept in mind. The normal modes of cis-formic acid are visualised by arrows and labelled according to the Herzberg nomenclature for $\mathrm{HCOOH}$, which is adopted for the deuterated isotopologues. For $\nu_{4}$ and $\nu_{5}$ of DCOOD, harmonic mode mixing into a symmetric and antisymmetric combination is predicted. See text for further details. 
Table 1 Raman jet (Ra. jet) band positions (in $\mathrm{cm}^{-1}$ ) of cis- and trans-formic acid and their deuterated isotopologues in comparison to literature values. Fermi resonance doublets are indicated by braces. Assignments which are somewhat tentative due to overlapping hot band and/or rovibrational structure are italicised (see text for discussion and ref. 62)

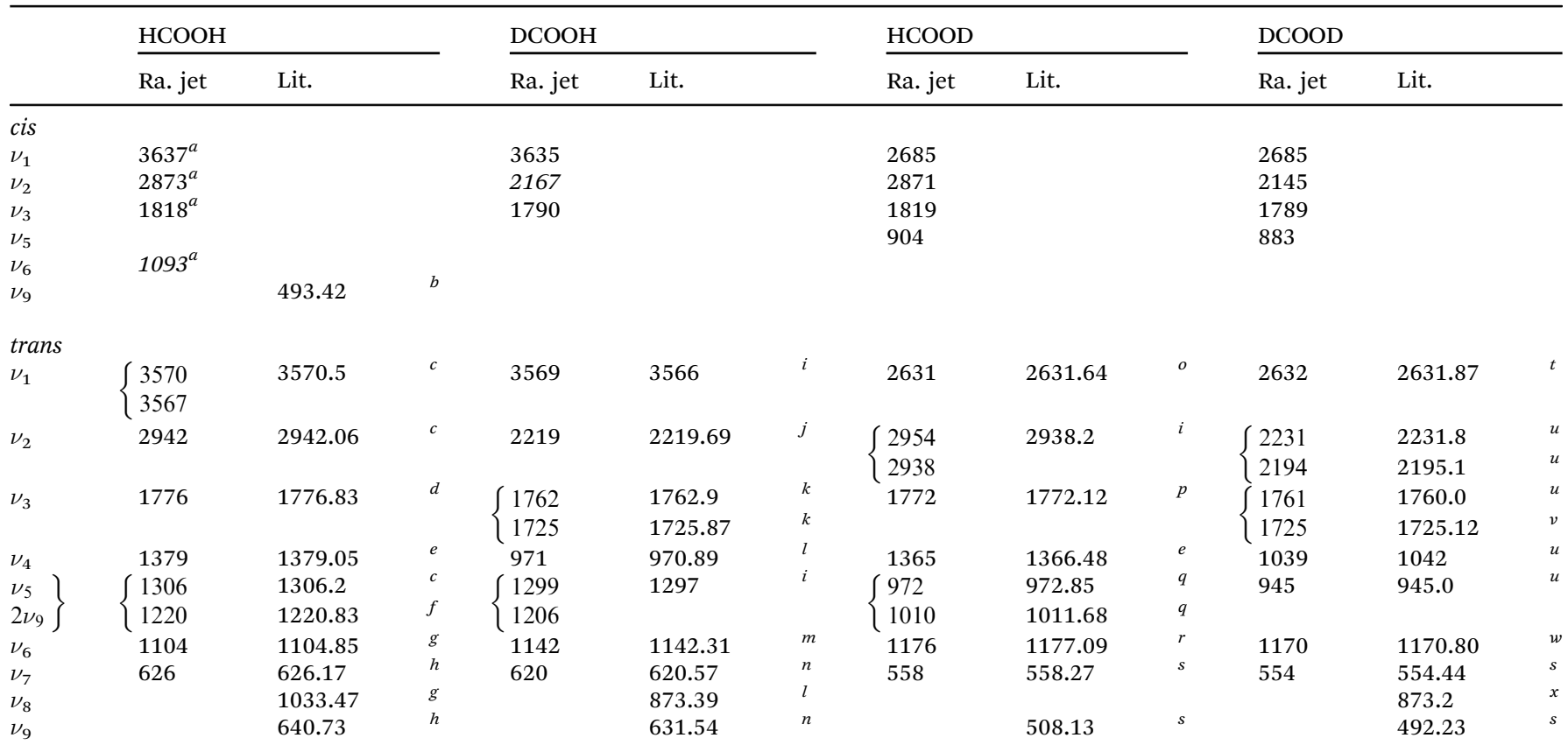

${ }^{a}$ Ref. 23 and $24 .{ }^{b}$ Ref. $22 .{ }^{c}$ Ref. 6 ; the band listed for $\nu_{5}$ was originally assigned to $2 \nu_{9} \cdot{ }^{d}$ Ref. 40 and $63 .{ }^{e}$ Ref. $10 .{ }^{f}$ Ref. 9 ; the band was originally assigned to the fundamental $\nu_{5} .{ }^{g}$ Ref. $64 .{ }^{h}$ Ref. 8 and $39 .{ }^{i}$ Ref. 5 ; the second band of the $\nu_{2}$ resonance doublet is reported at $2941.8 \mathrm{~cm}{ }^{-1}$, but corresponds to an impurity of $\mathrm{HCOOH}$ in the spectra and is therefore not listed here. ${ }^{j}$ Ref. $37 .{ }^{k}$ Ref. $65 .{ }^{l}$ Ref. $66 .{ }^{m}$ Ref. $67 .{ }^{n}$ Ref. $68 .{ }^{o}$ Ref. 69 . ${ }^{p}$ Ref. 70, see also ref. 71 and $72 .{ }^{q}$ Ref. $73 .{ }^{r}$ Ref. $74 .{ }^{s}$ Ref. 36. ${ }^{t}$ Ref. $75 .{ }^{u}$ Ref. $4 .{ }^{v}$ Ref. $7 .{ }^{w}$ Ref. $76 .{ }^{x}$ Ref. 33.

acid monomer can be found in Table 1 alongside the corresponding trans-bands and high resolution literature values wherever available. A detailed view of the cis-formic acid spectra can be found in the ESI $\dagger$ (Fig. S2-S5). The agreement between the newly determined Raman jet and literature band positions for trans-formic acid is generally within the experimental uncertainty of our set-up $\left( \pm 2 \mathrm{~cm}^{-1}, c f\right.$. Section 2$)$. A preliminary Raman jet study from our laboratory ${ }^{31}$ generally agrees with the trans-formic acid results reported here, within the previous, somewhat larger calibration error and apart from a few assignments. For cis-formic acid, the vibrational reference database has been extended by eleven new band positions. With one gas phase band position ${ }^{22}$ and four Raman jet values from previous studies ${ }^{23,24}$ for $c i s-\mathrm{HCOOH}$, the total number of $c i s$-formic acid fundamentals now amounts to sixteen.

A recent example of a high-level variational anharmonic $a b$ initio study on the formic acid monomer is an MCTDH study by Aerts et al. from $2020^{13}$ who have characterised the cisand trans-conformers of all three deuterated isotopologues. Due to the lack of environment-free experimental data on the higher-energy structure, the accuracy of their description could solely be evaluated for the global minimum trans-form. The new cis-formic acid band positions reported in this work also facilitate a performance evaluation for the higher-energy rotamer. For most modes, the deviations are below $2-3 \mathrm{~cm}^{-1}$. The largest band position discrepancy is observed for $\nu_{1}$ of cisDCOOH and amounts to $10 \mathrm{~cm}^{-1}$ followed by 9,4 , and $7 \mathrm{~cm}^{-1}$ for $\nu_{3}$ of $c i s$-DCOOH, cis-HCOOD and cis-DCOOD, respectively.

\subsection{Comparison of the Raman spectra of all four $\mathrm{H} / \mathrm{D}$ isotopologues}

An overview of the Raman spectra of the four H/D (trans-)formic acid isotopologues is shown in Fig. 2 for a nozzle temperature of $160{ }^{\circ} \mathrm{C}$ - a compromise between the absence of cluster signals and signal intensity. Fermi resonance doublets of the trans-rotamers are indicated by brackets. Hot bands are marked by ' $h$ ' and impurities due to H/D exchange reactions and/or the manufacturing process by a double dagger. The maximum of such impurities observed in the spectra amounts to 6(2)\% (see Table S1 in the ESI $\dagger$ for further details). To visualise and systematically analyse the spectral similarities and differences observed for the four H/D isotopologues, the cis-trans-shift is plotted against the absolute cis-band position for the five vibrations characterised with Raman jet spectroscopy and the sixth vibrational mode obtained from high resolution gas phase studies by Baskakov et al. ${ }^{8,22}$ in Fig. 3. In case of Fermi resonances of the respective trans-band, the band position of both resonance partners is shown and the symbol size reflects their relative intensity. For cis-formic acid, no signs of resonances were observed in our spectra, but this might be attributed to the relatively low intensity governed by the low abundance in the expansion.

The absolute band positions as well as cis-trans-shifts of the $\mathrm{O}-\mathrm{H}$ and $\mathrm{O}-\mathrm{D}$ stretching vibrations are insensitive to $\mathrm{C}-\mathrm{H}$ isotope exchange (Fig. 3). However, next to the $\mathrm{OH}$ stretching band of trans-HCOOH $\left(3570 \mathrm{~cm}^{-1}\right)$, one fairly strong band with an intensity ratio of one third of $\nu_{1}$ can be seen at $3567 \mathrm{~cm}^{-1}$ in 

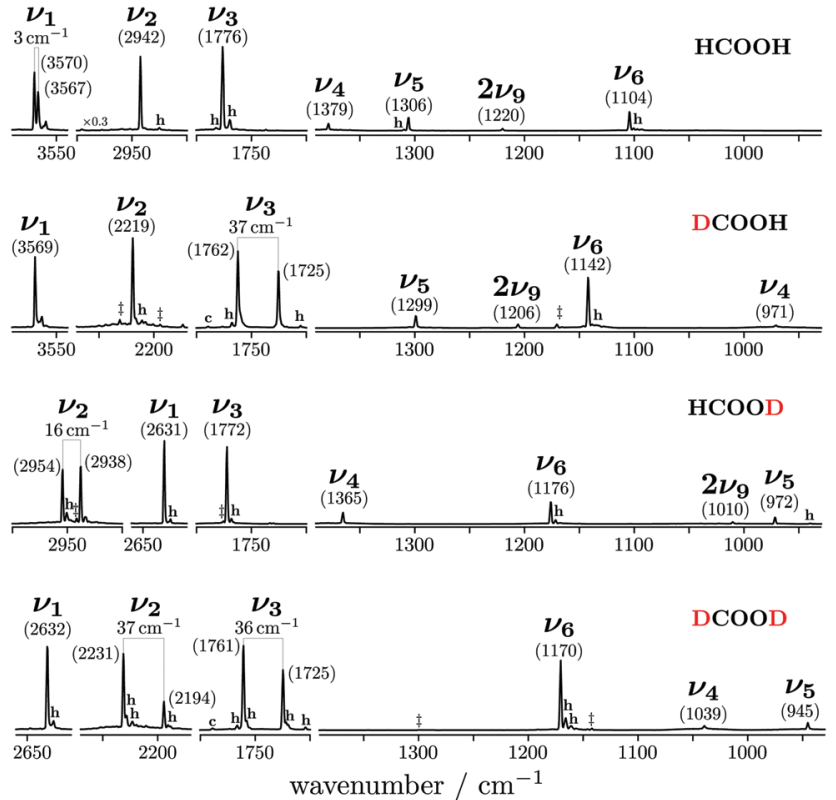

Fig. 2 Overview of the Raman jet spectra of the $O-H / D, C-H / D, C=O$, $\mathrm{C}-\mathrm{O}$ stretching as well as $\mathrm{C}-\mathrm{H} / \mathrm{D}$ and $\mathrm{O}-\mathrm{H} / \mathrm{D}$ in-plane bending vibrations of $\mathrm{HCOOH}, \mathrm{DCOOH}, \mathrm{HCOOD}$, and DCOOD recorded at a nozzle temperature of $160{ }^{\circ} \mathrm{C}$. Bands of pronounced resonance doublets between fundamentals $\nu_{i}$ and combination or overtone bands are indicated by brackets and $H, D$ impurities by double daggers. Non-isomeric hot and cis-rotamer bands are marked ' $h$ ' and ' $c$ ', respectively.

addition to a smaller third band at $3559 \mathrm{~cm}^{-1}$ (Fig. 2). Since the band position difference between the fundamental and the second band is very small, this does not affect the cis-trans-shift significantly ( $c f$. Fig. 3). A similar $\nu_{1}$-triad of trans-HCOOH has also been observed in helium nanodroplets, ${ }^{38}$ which the authors attributed to Fermi and Coriolis resonances. For a full understanding of the $\mathrm{OH}$ stretching dynamics in formic acid, a detailed characterisation of skeletal modes and their associated coupling pathways is required. ${ }^{77}$

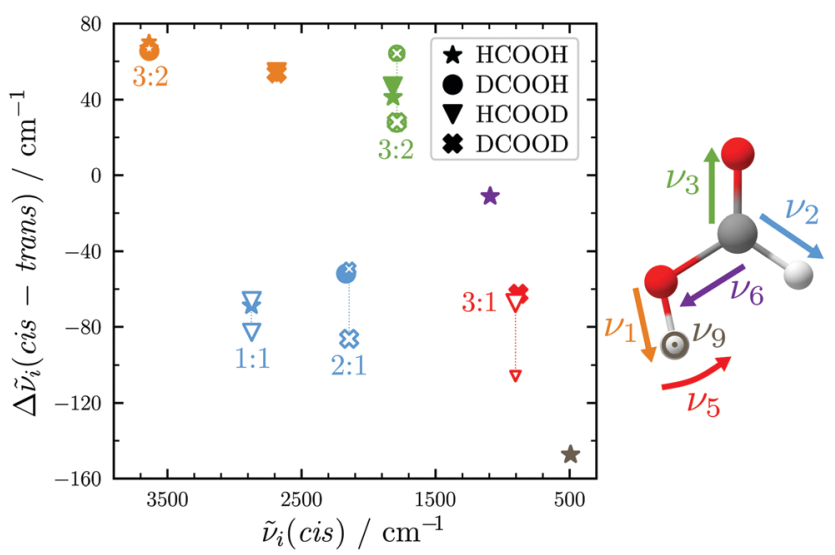

Fig. 3 cis-trans vibrational band position shifts plotted against the cisband positions for all H/D isotopologues of the formic acid monomer. The colour illustrates the type of vibration. For Fermi resonances, unfilled symbols are used and the band positions of both resonance partners are connected by dotted lines with the symbol size representing their relative intensity.
The $\mathrm{C}=\mathrm{O}$ stretch $\nu_{3}$ of trans-DCOOH and -DCOOD has a pronounced resonance (intensity ratio $3(0.5): 2)$ with the C-D out-of-plane bending vibration $2 \nu_{8}$ (Fig. 2 ).$^{65}$ The cis-trans-shift is again very similar for all isotopologues if one compares it against the resonance centre (Fig. 3).

The situation becomes different for the C-H/D stretching vibration $\nu_{2}$. For trans-HCOOD, Bertie et al. reported a resonance with the $\left(\nu_{3}+\nu_{6}\right)$ combination band, yet assigned it to an impurity of $\mathrm{HCOOH}\left(2941.8 \mathrm{~cm}^{-1}\right)$ in their spectra. ${ }^{5}$ We do, however, observe a resonance doublet with an intensity ratio close to $1: 1$ and an experimental splitting of $16 \mathrm{~cm}^{-1}$. The second band of the resonance doublet at $2954 \mathrm{~cm}^{-1}$ (Table 1) is likely overlayed by a dimer band in the spectra of Bertie et al. which they report at $2951.4 \mathrm{~cm}^{-1}$. The clear distinction between monomeric and dimeric contributions in the spectra via the temperature series is one of the advantages of the new Raman spectra reported in this work. Comparing against the resonance centre, the $\mathrm{C}-\mathrm{H}$ cis-trans-shift is insensitive to $\mathrm{O}-\mathrm{H}$ deuteration (Fig. 3). The same applies to the respective absolute cis-band position. The larger difference between the cis-trans-shifts of the C-D stretching vibrations (Fig. 3) can at least partially be ascribed to the Fermi resonance between $\nu_{2}$ and the $\left(\nu_{4}+\nu_{6}\right)$ combination band of trans-DCOOD. ${ }^{4}$ Interestingly, the isotope effect on the cis-C-D stretch is with $22 \mathrm{~cm}^{-1}$ much larger than for the $\mathrm{C}-\mathrm{H}, \mathrm{O}-\mathrm{D} / \mathrm{H}$ stretches, where these differences only amount to $\leq 2 \mathrm{~cm}^{-1}$ (cf. Table 1). This anomaly could be a result of an anharmonic perturbation that only occurs in one $\mathrm{O}-\mathrm{H} / \mathrm{D}$ isotopologue of the cis-rotamer, though this remains speculative due to the low intensity of the cis-contributions in our spectra. Another reason for this larger difference could be a misassignment of one of the two $c i s-\nu_{2}$ bands, most likely that of cis-DCOOH due to the spectral congestion governed by the rovibrational structure of the trans-band ( $c f$. Fig. S3 in the ESI $\dagger$ ). However, the good agreement of all $c i s-\nu_{2}$ bands with the highlevel prediction of Aerts et al. ${ }^{13}$ (deviations below $3 \mathrm{~cm}^{-1}$ ) does not support this conjecture. Besides, close to the cis-band position of cis-DCOOD $\left(2145 \mathrm{~cm}^{-1}\right)$, there are no other hot bands in the DCOOH spectrum and vice versa (Fig. S3 in the ESI $\dagger$ ).

Similar observations with regard to the absolute cis-band position as well as Fermi resonance governed difference in cis-trans-shift (cf. Table 1 and Fig. 3 ) apply to the O-D in-plane bending vibration $\nu_{5}$. However, there is another factor that sets the trans- (and cis-)DCOOD bending vibration apart from that of the other H/D isotopologues, which can be understood by taking a closer look at the $\nu_{5} / 2 \nu_{9}$ Fermi resonance across all H/D isotopologues.

\subsection{The $\nu_{5} / 2 \nu_{9}$ Fermi resonance of trans-formic acid}

The $\nu_{5} / 2 \nu_{9}$ Fermi resonance is amongst the most prominent ones found for trans- $\mathrm{HCOOH}$ and involves the $\mathrm{O}-\mathrm{H}$ in-plane bend $\nu_{5}$ and the overtone of the large-amplitude $\mathrm{O}-\mathrm{H}$ torsion $2 \nu_{9}$ (Fig. 1). In a high resolution study of the respective hot bands in 2019, Hull et al. showed that the labels of the two resonance partners at $1306 \mathrm{~cm}^{-1}$ and at $1220 \mathrm{~cm}^{-1}$ need to be switched, as the overtone was shown to be lower in energy than the fundamental. ${ }^{27}$ This Fermi resonance is also present in 
trans-DCOOH as well as in trans-HCOOD but seemingly absent in trans-DCOOD. For the cis-conformers, this Fermi resonance is not predicted, ${ }^{11-13}$ which makes a combination of both species valuable for vibrational benchmarking.

A more detailed view of the Raman spectra of this resonance for all four isotopologues can be found in Fig. 4, which facilitates new insight into the strength of the resonance as well as into the suggested label switch for trans- $\mathrm{HCOOH}$. Interestingly, the higher-energy band of trans- $\mathrm{HCOOH}$ at $1306 \mathrm{~cm}^{-1}$ is about seven times more intense than the band at $1220 \mathrm{~cm}^{-1}$, though the latter was previously assigned to the fundamental. The infrared spectra of $\mathrm{HCOOH}$ shown alongside the corresponding Raman spectra in Fig. 5 indicate an inverse situation where the lower energy band at $1220 \mathrm{~cm}^{-1}$ is more intense and the $1306 \mathrm{~cm}^{-1}$ band is barely visible at the employed conditions. This explains why based on solely the infrared spectra, the more intense band at $1220 \mathrm{~cm}^{-1}$ was previously assigned to the fundamental transition. A differing intensity ratio of a Fermi resonance in infrared and Raman spectra is rather unexpected, as usually the overtone (or combination band) is 'dark', meaning that it obtains intensity primarily via the anharmonic resonance with the 'bright' fundamental. As

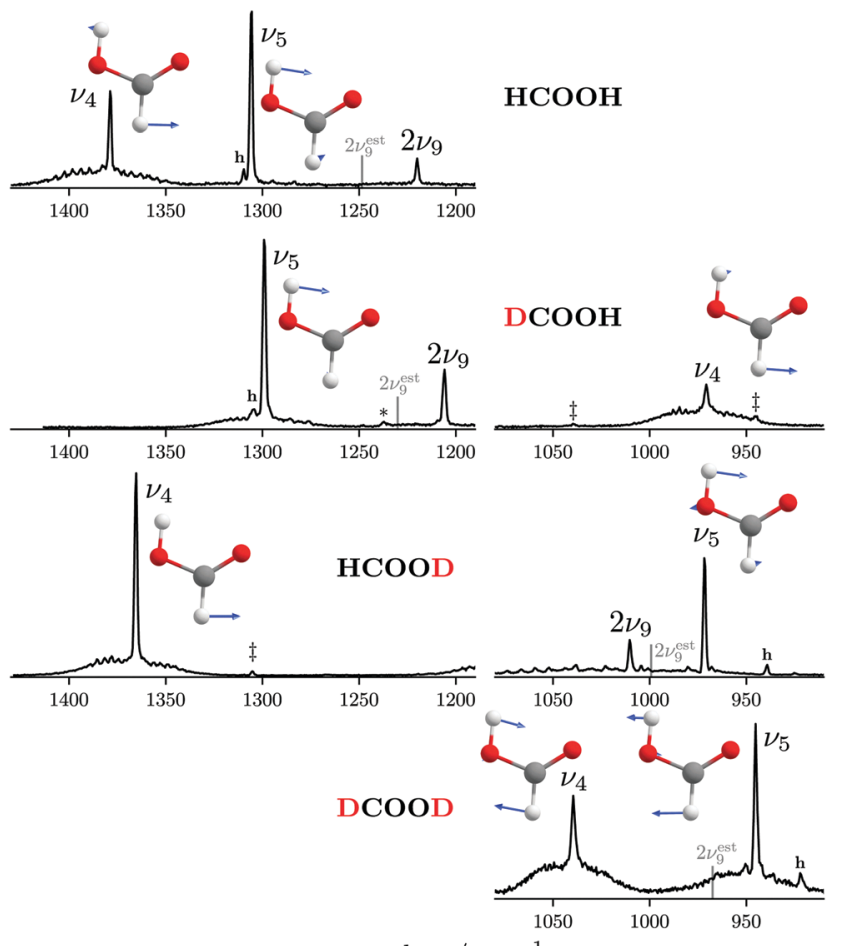

wavenumber $/ \mathrm{cm}^{-1}$

Fig. 4 Raman jet spectra of the $\mathrm{C}-\mathrm{H} / \mathrm{D}$ in-plane bending vibration $\nu_{4}$ and the $\mathrm{O}-\mathrm{H} / \mathrm{D} \nu_{5} / 2 \nu_{9}$ Fermi resonance of all four $\mathrm{H} / \mathrm{D}$ isotopologues of the formic acid monomer recorded at a nozzle temperature of $160{ }^{\circ} \mathrm{C}$. Cluster bands are marked with an asterisk, hot bands with ' $h$ ', and $H, D$ impurities by double daggers. The band position of the overtone $2 \nu_{9}$ has been estimated from twice the experimental band position of $\nu_{9}$ (see Table 1 for band positions) by subtracting twice the diagonal anharmonicity matrix element reported in ref. 27 and is shown by a grey line. The normal modes of $\nu_{5}$ and $\nu_{4}$ are shown as an inset. Additional experimental details can be found in Section 2 and in the ESI. $\dagger$

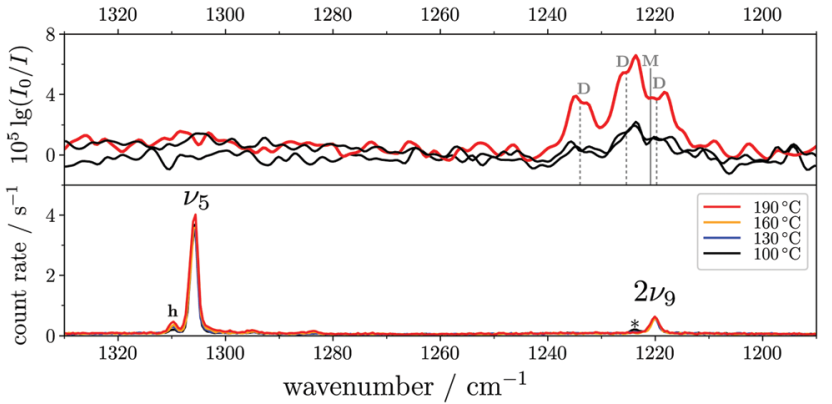

Fig. 5 FTIR (top) and Raman (bottom) jet spectra of trans-HCOOH in the $\mathrm{O}-\mathrm{H}$ in-plane bending region $\left(\nu_{5}\right)$. The FTIR spectra have been recorded at increasing concentrations of $<0.01-0.05 \%$ in helium at a reservoir pressure of 560 mbar with 1750-2130 co-added scans. The Raman spectra $(<0.2 \%$ in helium, reservoir pressure $500 \mathrm{mbar}$, recording time $6 \times 300 \mathrm{~s})$ have been intensity-scaled to the $\nu_{6}$ band (not shown) of trans- $\mathrm{HCOOH}$ with the lowest intensity amongst the four nozzle temperatures $\left(100-190{ }^{\circ} \mathrm{C}\right)$. Assignments of monomer (M) and dimer (D) contributions to the band between $1240-1210 \mathrm{~cm}^{-1}$ in the FTIR spectra were taken from ref. 9. Clusters in the Raman spectrum are marked with an asterisk.

such, this infrared/Raman intensity difference implies that the overall comparably low-intense fundamental $\nu_{5}$ ( $c f$. Fig. 1 for relative Raman scattering cross-sections and Table S3 in the ESI $\dagger$ for the predicted IR intensities) 'steals' intensity from the brighter overtone in one of the spectra and the dark overtone 'steals' intensity from the brighter fundamental in the other. Considering that Raman scattering cross-sections of overtones (or combination bands) are typically about two orders of magnitude lower than those of fundamentals, ${ }^{78}$ whereas this difference typically amounts to about one order of magnitude in the infrared, it is more plausible that the infrared $\nu_{9}$ overtone is brighter than the $\nu_{5}$ fundamental. This is in line with the suggested label switch of the resonance partners by Hull et al. ${ }^{27}$ which was also proposed in the VCI and MCTDH studies from $2016^{11}$ and $2018 .^{12}$

As aforementioned, the $\nu_{5} / 2 \nu_{9}$ Fermi resonance is also present in $\mathrm{DCOOH}$ with a slightly larger splitting $\left(93 \mathrm{~cm}^{-1}\right.$ versus $86 \mathrm{~cm}^{-1}$ for $\mathrm{HCOOH}$ ) and a similar intensity ratio $(7(2): 1)$. In case of $\mathrm{DCOOH}$, Bertie et al. ${ }^{5}$ correctly assigned the band at $1299 \mathrm{~cm}^{-1}\left(1297 \mathrm{~cm}^{-1}\right.$ in ref. 5) to the O-H in-plane bending vibration $\nu_{5}$, whereas the corresponding band of $\mathrm{HCOOH}$ at $1306 \mathrm{~cm}^{-1}\left(1307 \mathrm{~cm}^{-1}\right.$ in ref. 4) was assigned to $2 \nu_{9}$ in their publication. ${ }^{4}$ For the O-deuterated isotopologues, the $\nu_{5} / 2 \nu_{9}$ Fermi resonance is only observed for HCOOD, where the $\nu_{9}$ overtone is higher in energy $\left(1011.68 \mathrm{~cm}^{-1}\right)$ than the $\nu_{5}$ fundamental $\left(972.85 \mathrm{~cm}^{-1}\right){ }^{73}$ The intensity ratio and splitting between both bands is distinctly smaller (1(1): 3 versus $7(2): 1$ and 38 instead of $86 / 93 \mathrm{~cm}^{-1}$ ), which is consistent with a weakening of the resonance for the smaller OD amplitudes.

The absence or at least pronounced weakness of the $\nu_{5} / 2 \nu_{9}$ resonance in trans-DCOOD ( $c f$. expected band position of $2 \nu_{9}$ in Fig. 4 which has been estimated from $2 \times\left(\nu_{9}\right)$ assuming an anharmonic correction of twice the anharmonicity matrix element $x_{99}$ as reported in ref. 27) can be understood in the comprehensive analysis of all four isotopologues. Fig. 2 shows that the C-D bend of DCOOH and O-D bend of HCOOD, which are estimates for the expected band positions of $\nu_{4}$ and $\nu_{5}$ in 
trans-DCOOD, are nearly isoenergetic at $971 / 972 \mathrm{~cm}^{-1}$. In the DCOOD spectrum, they are shifted up $\left(1039 \mathrm{~cm}^{-1}\right)$ and down $\left(945 \mathrm{~cm}^{-1}\right)$ in energy, indicating harmonic mixing due to neardegeneracies. This mixing is further supported by the unusually low ratio of the $\mathrm{Q}$ branch with respect to the rotational contour found for $\nu_{5}$ of trans-DCOOD (a feature of $\nu_{4}, c f$. Fig. 4), which might result from substantial mixing with $\nu_{4}$. Pointing in that same direction are different harmonic frequency calculations that unanimously predict a mixing into a symmetric and an antisymmetric combination for cis- and trans-DCOOD (HF, MP2, CCSD(T), and DFT, all with an aVTZ basis set, $c f$. inset in Fig. 4 for normal modes of the trans-rotamers).

For a closer scrutiny of this mixing across the four H/D isotopologues, harmonic frequencies of trans-formic acid were scanned for $\mathrm{C}-\mathrm{H}$ proton masses between 1 and $2 m\left({ }^{1} \mathrm{H}\right)$. The harmonic wavenumbers of $\nu_{4}, \nu_{5}, \nu_{6}, 2 \nu_{7}$, and $2 \nu_{9}$ (all $\mathrm{A}^{\prime}$ symmetry) for both possible scans (trans- $\mathrm{HCOOH} \rightarrow$ trans$\mathrm{DCOOH}$, trans-HCOOD $\rightarrow$ trans-DCOOD) are plotted for B3LYP-D3(BJ)/aVTZ in Fig. 6. Strong mixing between $\nu_{4}, \nu_{5}$, and $\nu_{6}$ is observed in these mass-scans with avoided crossings on the order of 60-110 $\mathrm{cm}^{-1}$. Accidentally, however, an avoided crossing of $\nu_{4}$ and $\nu_{5}{ }^{34}$ coincides with an integer (even) mass in one case, i.e., DCOOD. Additional scans at other levels of theory (Fig. S1 in the ESI $\dagger$ ) show the same qualitative behaviour. As such, the potential absence of the $\nu_{5} / 2 \nu_{9}$ Fermi resonance in DCOOD is in part a coincidence of an avoided crossing that detunes two otherwise moderately resonant states. This alone, however, does not explain the absence of the overtone $2 \nu_{9}$ in the DCOOD spectra entirely, as $2 \nu_{9}$ could gain in intensity via coupling to $\nu_{4}$ which exhibits $\nu_{5}$ character. The $2 \nu_{9}$ band of DCOOD might not gain sufficient intensity in this coupling triad to be observed under the employed experimental conditions. A comparison of measurements with perpendicular and parallel laser polarisation ${ }^{78}$ can be used to reduce the rotational contour via subtraction. This depolarised spectrum of DCOOD ( $c f$. Fig. S5 in the ESI $\dagger$ ) shows that no distinct $2 \nu_{9}$ band is hidden under the rotational contour of $\nu_{5}$ of DCOOD in our spectra, providing additional affirmation of its weakness.

Overall, this harmonic mode mixing could be another reason for the differences observed for the cis-trans-shifts as well as cis-band positions (mixing is also predicted for cis-DCOOD) of HCOOD and DCOOD (Fig. 3). Subtle mass changes such as ${ }^{13} \mathrm{C}$ isotopic substitution ${ }^{28}$ might allow for more insight, though this is experimentally too elaborate without further theoretical support.

\subsection{Fermi resonance analysis for the $H / D$ isotopologues of trans-formic acid}

For vibrational benchmarking of near-degeneracies, not only the energetic order of the two interacting states needs to be predicted correctly by a quantum chemical model, but also their energy difference (spectral splitting $|\Delta \tilde{\nu}|$ ) as well as the spectral intensity ratio $R$ (here $I_{\text {high }} / I_{\text {low }}$ ). From these two quantities, the Fermi resonance coupling constant $\left|W_{\text {Fermi }}^{\exp }\right|$ can be calculated from eqn (2) under the assumption that the dark state has a negligible intensity, ${ }^{79}$ which allows for an estimate of the strength of the resonance.

$$
\left|W_{\text {Fermi }}^{\exp }\right|=\frac{|\Delta \tilde{\nu}| \sqrt{R}}{(1+R)}
$$

These effective values $\left|W_{\text {Fermi }}^{\exp }\right|$ for all trans-formic acid Fermi resonances observed in this work are listed in Table 2 alongside model values $\left|W_{\mathrm{Fermi}}^{\text {calc }}\right|$ calculated from a quartic force field based on the PES of Tew and Mizukami ${ }^{11}$ ( $c f$. ESI $\dagger$ for further details). For $\nu_{2}$ of HCOOD, only the $\mathrm{Q}$ branches of the vibrational bands were integrated to determine $\left|W_{\text {Fermi }}^{\exp }\right|(c f$. Fig. S3 in the ESI $\dagger$ ). The neglect of the overlapping rotational contours for $\nu_{2} /\left(\nu_{3}+\nu_{6}\right)$ of HCOOD should not impact $\left|W_{\mathrm{Fermi}}^{\exp }\right|$ much, as the two resonance partners are nearly equal in intensity
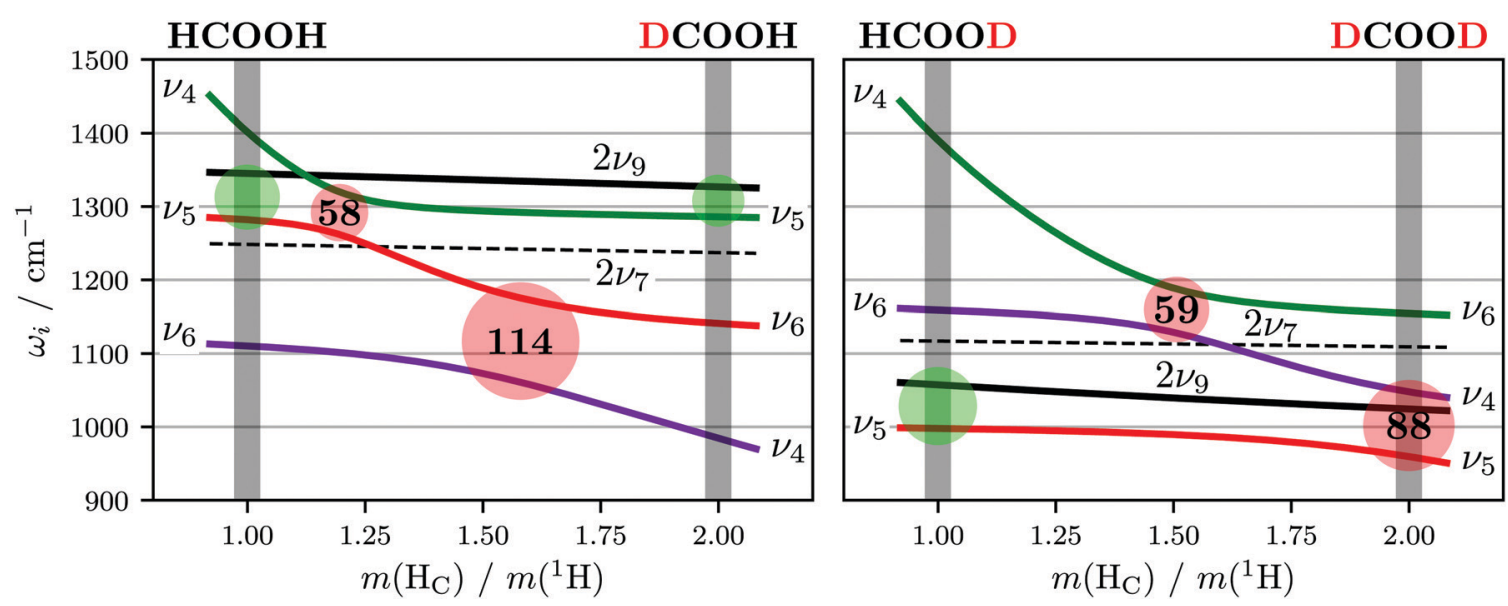

Fig. 6 Harmonic wavenumbers (in $\mathrm{cm}^{-1}$, at the B3LYP-D3(BJ)/aVTZ level) of $\mathrm{A}^{\prime}$ symmetric fundamentals and overtones in the spectral windows between 900 and $1500 \mathrm{~cm}^{-1}$ as a function of the relative $\mathrm{C}-\mathrm{H}$ proton mass of trans-formic acid (left $\mathrm{O}-\mathrm{H}$, right $\mathrm{O}-\mathrm{D}$ ). Grey bars indicate fractional masses which equal the mass of hydrogen or deuterium. Harmonically avoided crossing due to mode-mixing is indicated by a red disk in the interaction region, in which twice the coupling constant $2 W$ is printed in bold letters. Green disks highlight the Fermi resonance-coupled states $\nu_{5}$ and $2 \nu_{9}$ in trans$\mathrm{HCOOH},-\mathrm{DCOOH}$, and -HCOOD. 
Table 2 Resonance analysis for Fermi resonance split fundamentals of the H/D isotopologues of trans-formic acid. The band centres for each doublet are reported in units of $\mathrm{cm}^{-1}$, where the more intense bands are printed in bold letters. The experimental (exp) value of the Fermi resonance coupling constant $\left|W_{\text {Fermi }}\right|$ (in $\mathrm{cm}^{-1}$ ) has been calculated according to eqn (2) and its error bars are computed using Gaussian error propagation with band centre uncertainties of $\pm 2 \mathrm{~cm}^{-1}$ and integrated band intensity errors of $\pm 20 \%$. The integrated intensities / are given with respect to the lower-intensity contribution. The calculated (calc) value of the coupling constant has been obtained from the quartic force field of the analytic PES by Tew and Mizukami (see ESI for further details)

\begin{tabular}{lccclllr}
\hline System & $\nu_{i}$ & $\tilde{\nu}_{\text {high }}$ & $\tilde{\nu}_{\text {low }}$ & $I_{\text {high }}$ & $I_{\text {low }}$ & $\operatorname{Exp}$ & Calc \\
\hline HCOOH & $\nu_{1}$ & $\mathbf{3 5 7 0}$ & 3567 & $3(0.5)$ & 2 & $2(2)$ & 0.3 \\
& & & & & & & \\
HCOOD & $\nu_{2}$ & 2954 & $\mathbf{2 9 3 8}$ & $1(0.5)$ & 1 & $8(2)^{a}$ & 8.7 \\
DCOOD & $\nu_{2}$ & $\mathbf{2 2 3 1}$ & 2194 & $2(1)$ & 1 & $17(2)$ & 18.9 \\
& & & & & & & \\
DCOOH & $\nu_{3}$ & $\mathbf{1 7 6 2}$ & 1725 & $3(0.5)$ & 2 & $18(2)$ & 18.3 \\
DCOOD & $\nu_{3}$ & $\mathbf{1 7 6 1}$ & 1725 & $3(0.5)$ & 2 & $18(2)$ & 18.1 \\
& & & & & & & \\
HCOOH & $\nu_{5}$ & $\mathbf{1 3 0 6}$ & 1220 & $7(2)$ & 1 & $28(4)$ & 39.6 \\
DCOOH & $\nu_{5}$ & $\mathbf{1 2 9 9}$ & 1206 & $7(2)$ & 1 & $31(4)$ & 42.7 \\
HCOOD & $\nu_{5}$ & 1010 & $\mathbf{9 7 2}$ & $1(1)$ & 3 & $17(2)^{b}$ & 16.8 \\
DCOOD & $\nu_{5}$ & & $\mathbf{9 4 5}$ & & & & 3.3
\end{tabular}

${ }^{a}$ Only Q branches (without additional substructure) were integrated to determine $\left|W_{\mathrm{Fermi}}^{\mathrm{exp}}\right|{ }^{b}$ Determined from a depolarised spectrum (see bottom of Fig. S5 in the ESI).

(cf. Fig. 2 and Table 2), so that their contributions to the rotational contour should also be similar. For $\nu_{5} / 2 \nu_{9}$ of HCOOD, there seems to be a broad rotational substructure which cannot be easily disentangled. Therefore, additional depolarisation measurements were performed (Fig. S5 in the ESI $\dagger$ ) and $\left|W_{\text {Fermi }}^{\exp }\right|$ was determined from these spectra.

As expected from the small spectral separation $\Delta \tilde{\nu}=3 \mathrm{~cm}^{-1}$, the Fermi resonance of $\nu_{1}$ of $\mathrm{HCOOH}$ is the weakest observed in this work with a coupling matrix element $\left|W_{\text {Fermi }}^{\exp }\right|$ of solely 2(2) $\mathrm{cm}^{-1}$. It agrees with the very small predicted value $\left|W_{\text {Fermi }}^{\text {calc }}\right|$ between $\nu_{1}$ and the $\left(\nu_{2}+\nu_{7}\right)$ combination band, although the third band in the Raman spectra and the resonance triad observed in helium nanodroplets ${ }^{38}$ indicate a more complex interaction than a simple two level resonance. Also rather weak is the $\nu_{2}$ Fermi resonance of HCOOD with $8(2) \mathrm{cm}^{-1}$. Again, $\left|W_{\text {Fermi }}^{\text {calc }}\right|$ and $\left|W_{\text {Fermi }}^{\exp }\right|$ match rather well, which supports the assignment by Bertie et $a l^{5}{ }^{5}$ who ascribed the resonance partner to the $\left(\nu_{3}+\nu_{6}\right)$ combination band. The strength of the $\nu_{3} / 2 \nu_{8}$ Fermi resonance observed for the C-deuterated isotopologues is near-identical and accidentally very similar to that of $\nu_{2}$ of DCOOD ( $c f$. Table 2). For all three resonances, the experimental and predicted Fermi coupling matrix elements agree within the experimental error bars.

For the $\nu_{5} / 2 \nu_{9}$ resonance doublet, a distinct strength variation is observed across the four isotopologues - it is largest for $\mathrm{DCOOH}\left(31(4) \mathrm{cm}^{-1}\right)$, decreases from $\mathrm{HCOOH}\left(28(4) \mathrm{cm}^{-1}\right)$ to HCOOD $\left(17(2) \mathrm{cm}^{-1}\right)$, and remains undetected for DCOOD (cf. Fig. 4). As for most other resonance doublets, $\left|W_{\text {Fermi }}^{\text {calc }}\right|$ of HCOOD matches the experimental value within the error bars. The calculated coupling constants $\left|W_{\text {Fermi }}^{\text {calc }}\right|$ of $\mathrm{HCOOH}$ and
DCOOH are $12 \mathrm{~cm}^{-1}$ larger than the experimental values. These findings seem to contradict the assumption of a completely dark state in case of $2 \nu_{9}$ of the two $\mathrm{O}-\mathrm{H}$ isotopologues (cf. eqn (2)). Further investigation of this might be worthwhile. Overall, this is just one of many examples where anharmonic Raman intensities could prove to be very helpful.

\section{Conclusions}

After over eighty years of experimental research since the first publication on the formic acid monomer (and dimer) by Bonner and Hofstadter in $1938,{ }^{32}$ the vibrational spectra of the simplest carboxylic acid are still not yet fully understood. The most notable missing vibrational information concerns its higher-energy cis-conformation, particularly that of the deuterated isotopologues of formic acid, where no perturbation-free band positions were known prior to this work. Recently, Raman jet spectroscopy in combination with thermal excitation was used to increase the number of $c i s-\mathrm{HCOOH}$ fundamentals from one to five. ${ }^{24}$ In this work, we have extended this technique to cis-HCOOD, -DCOOH, and-DCOOD and were able to assign the bands of all $\mathrm{O}-\mathrm{H} / \mathrm{D}, \mathrm{C}-\mathrm{H} / \mathrm{D}, \mathrm{C}=\mathrm{O}$ stretching as well as those of the two $\mathrm{O}-\mathrm{D}$ in-plane bending vibrations.

For the trans-formic acid monomer, although all but one fundamental vibration of the H/D isotopologues have already been determined, there is still ambiguity concerning assignments of overtones, combination bands, and Fermi resonance partners. ${ }^{11,12}$ A comparison of the latter amongst all four isotopologues has proven to be very insightful, particularly for the $\nu_{5} / 2 \nu_{9}$ resonance. This resonance is found to be weakest for HCOOD and appears to be absent in DCOOD. For $\mathrm{HCOOH}$ and $\mathrm{DCOOH}$, similar coupling strengths are predicted, though from our Raman spectra we obtain smaller experimental coupling constants for both. This discrepancy between theory and experiment hints at a more complicated resonance mixing than that of a 'bright' fundamental interacting with a 'dark' overtone. The reason for the absence of this Fermi resonance in DCOOD might be harmonic mode mixing between $\nu_{4}$ and $\nu_{5}$ that detunes the resonance, yet for exact conclusions, further theoretical investigation is necessary.

Non-isomeric hot bands (see for example Fig. S2-S5 in the $\mathrm{ESI} \dagger$ ) are another valuable benchmarking target in addition to the cis-fundamentals and the Fermi resonance coupling matrix elements $\left|W_{\text {Fermi }}\right|$, as these facilitate an analysis of weaker anharmonicity signatures $x_{i j} \cdot{ }^{24,44}$ For a thorough analysis of the large number of these hot bands observed in our spectra, a close collaboration between theory and experiment is vital. This represents one of the future directions of this work. The wealth of isomerically hot, yet rotationally cold formic acid monomer data provided in this contribution significantly advances its standing as a benchmarking reference system and hopefully triggers further theoretical investigation on this system.

\section{Conflicts of interest}

Ther e are no conflicts to declare. 


\section{Acknowledgements}

This work was funded by the Deutsche Forschungsgemeinschaft (DFG, German Research Foundation) - 389479699/GRK2455 and 405832858. The authors thank M. Schwarzer for his help with early DCOOD measurements and Z. Xue for a preliminary Raman jet study of the trans-formic acid spectra. ${ }^{31}$ A. Nejad thanks the Fonds der Chemischen Industrie (FCI) for an attractive scholarship.

\section{Notes and references}

1 R. Zander, P. Duchatelet, E. Mahieu, P. Demoulin, G. Roland, C. Servais, J. V. Auwera, A. Perrin, C. P. Rinsland and P. J. Crutzen, Atmos. Chem. Phys., 2010, 10, 10047-10065.

2 D. B. Millet, M. Baasandorj, D. K. Farmer, J. A. Thornton, K. Baumann, P. Brophy, S. Chaliyakunnel, J. A. de Gouw, M. Graus, L. Hu, A. Koss, B. H. Lee, F. D. Lopez-Hilfiker, J. A. Neuman, F. Paulot, J. Peischl, I. B. Pollack, T. B. Ryerson, C. Warneke, B. J. Williams and J. Xu, Atmos. Chem. Phys., 2015, 15, 6283-6304.

3 I. C. Hisatsune and J. Heicklen, Can. J. Spectrosc., 1973, 18, 135-142.

4 J. E. Bertie and K. H. Michaelian, J. Chem. Phys., 1982, 76, 886-894.

5 J. E. Bertie, K. H. Michaelian, H. H. Eysel and D. Hager, J. Chem. Phys., 1986, 85, 4779-4789.

6 M. Freytes, D. Hurtmans, S. Kassi, J. Liévin, J. Vander Auwera, A. Campargue and M. Herman, Chem. Phys., 2002, 283, 47-61.

7 F. Madeja, A. Hecker, S. Ebbinghaus and M. Havenith, Spectrochim. Acta, Part A, 2003, 59, 1773-1782.

8 O. I. Baskakov, E. A. Alekseev, R. A. Motiyenko, J. Lohilahti, V.-M. Horneman, S. Alanko, B. P. Winnewisser, I. R. Medvedev and F. C. De Lucia, J. Mol. Spectrosc., 2006, 240, 188-201.

9 K. G. Goroya, Y. Zhu, P. Sun and C. Duan, J. Chem. Phys., 2014, 140, 164311.

10 W. Luo, Y. Zhang, W. Li and C. Duan, J. Mol. Spectrosc., 2017, 334, 22-25.

11 D. P. Tew and W. Mizukami, J. Phys. Chem. A, 2016, 120, 9815-9828.

12 F. Richter and P. Carbonnière, J. Chem. Phys., 2018, 148, 064303.

13 A. Aerts, P. Carbonnière, F. Richter and A. Brown, J. Chem. Phys., 2020, 152, 024305.

14 W. H. Hocking, Z. Naturforsch., A, 1976, 31, 1113-1121.

15 M. Winnewisser, B. P. Winnewisser, M. Stein, M. Birk, G. Wagner, G. Winnewisser, K. M. T. Yamada, S. P. Belov and O. I. Baskakov, J. Mol. Spectrosc., 2002, 216, 259-265.

16 M. Pettersson, J. Lundell, L. Khriachtchev and M. Räsänen, J. Am. Chem. Soc., 1997, 119, 11715-11716.

17 E. M. S. Maçôas, J. Lundell, M. Pettersson, L. Khriachtchev, R. Fausto and M. Räsänen, J. Mol. Spectrosc., 2003, 219, 70-80.

18 A. Domanskaya, K. Marushkevich, L. Khriachtchev and M. Räsänen, J. Chem. Phys., 2009, 130, 154509.
19 L. O. Paulson, D. T. Anderson, J. Lundell, K. Marushkevich, M. Melavuori and L. Khriachtchev, J. Phys. Chem. A, 2011, 115, 13346-13355.

20 E. L. Sibert III, J. Chem. Phys., 2019, 150, 090901.

21 F. Ito, Comput. Theor. Chem., 2019, 1161, 18-25.

22 O. I. Baskakov, V.-M. Horneman, J. Lohilahti and S. Alanko, J. Mol. Struct., 2006, 795, 49-53.

23 K. A. E. Meyer and M. A. Suhm, J. Chem. Phys., 2018, 149, 104307.

24 K. A. E. Meyer and M. A. Suhm, Chem. Sci., 2019, 10, 6285-6294.

25 G. Giubertoni, O. O. Sofronov and H. J. Bakker, J. Phys. Chem. Lett., 2019, 10, 3217-3222.

26 J. Demaison, M. Herman and J. Liévin, J. Chem. Phys., 2007, 126, 164305.

27 K. Hull, T. Wells, B. E. Billinghurst, H. Bunn and P. L. Raston, AIP Adv., 2019, 9, 015021.

28 R. L. Redington, J. Mol. Spectrosc., 1977, 65, 171-189.

29 L. G. Bonner and J. S. Kirby-Smith, Phys. Rev., 1940, 57, 1078.

30 A. Olbert-Majkut, J. Ahokas, J. Lundell and M. Pettersson, Chem. Phys. Lett., 2009, 468, 176-183.

31 Z. Xue, Raman spectroscopy of carboxylic acid and water aggregates, PhD thesis, Logos Berlin, Berlin, 2011.

32 L. G. Bonner and R. Hofstadter, J. Chem. Phys., 1938, 6, 531-534.

33 V. Z. Williams, J. Chem. Phys., 1947, 15, 243-251.

34 J. K. Wilmshurst, J. Chem. Phys., 1956, 25, 478-480.

35 R. C. Millikan and K. S. Pitzer, J. Chem. Phys., 1957, 27, 1305-1308.

36 O. I. Baskakov, H. Bürger and W. Jerzembeck, J. Mol. Spectrosc., 1999, 193, 33-45.

37 T. L. Tan, K. L. Goh, P. P. Ong and H. H. Teo, J. Mol. Spectrosc., 1999, 198, 387-392.

38 F. Madeja, P. Markwick, M. Havenith, K. Nauta and R. E. Miller, J. Chem. Phys., 2002, 116, 2870-2878.

39 A. Perrin, J.-M. Flaud, B. Bakri, J. Demaison, O. Baskakov, S. Sirota, M. Herman and J. Auwera, J. Mol. Spectrosc., 2002, 216, 203-213.

40 A. Perrin, J. Vander Auwera and Z. Zelinger, J. Quant. Spectrosc. Radiat. Transfer, 2009, 110, 743-755.

41 P. Das, C. J. Knapp and W. Jäger, J. Mol. Spectrosc., 2017, 341, 17-22.

42 A. Nejad, E. Meyer and M. A. Suhm, J. Phys. Chem. Lett., 2020, 11, 5228-5233.

43 F. Kollipost, R. Wugt Larsen, A. V. Domanskaya, M. Nörenberg and M. A. Suhm, J. Chem. Phys., 2012, 136, 151101.

44 T. Forsting and M. Suhm, Curry-Jet SETUP, DOI: 10.6084/ m9.figshare.6395840.v1.

45 M. Gawrilow and M. A. Suhm, Phys. Chem. Chem. Phys., 2020, 22, 15303-15311.

46 K. A. E. Meyer and M. A. Suhm, J. Chem. Phys., 2017, 147, 144305.

47 M. A. Suhm and F. Kollipost, Phys. Chem. Chem. Phys., 2013, 15, 10702-10721. 
48 M. J. Frisch, G. W. Trucks, H. B. Schlegel, G. E. Scuseria, M. A. Robb, J. R. Cheeseman, G. Scalmani, V. Barone, B. Mennucci, G. A. Petersson, H. Nakatsuji, M. Caricato, X. Li, H. P. Hratchian, A. F. Izmaylov, J. Bloino, G. Zheng, J. L. Sonnenberg, M. Hada, M. Ehara, K. Toyota, R. Fukuda, J. Hasegawa, M. Ishida, T. Nakajima, Y. Honda, O. Kitao, H. Nakai, T. Vreven, J. A. Montgomery, Jr., J. E. Peralta, F. Ogliaro, M. Bearpark, J. J. Heyd, E. Brothers, K. N. Kudin, V. N. Staroverov, R. Kobayashi, J. Normand, K. Raghavachari, A. Rendell, J. C. Burant, S. S. Iyengar, J. Tomasi, M. Cossi, N. Rega, J. M. Millam, M. Klene, J. E. Knox, J. B. Cross, V. Bakken, C. Adamo, J. Jaramillo, R. Gomperts, R. E. Stratmann, O. Yazyev, A. J. Austin, R. Cammi, C. Pomelli, J. W. Ochterski, R. L. Martin, K. Morokuma, V. G. Zakrzewski, G. A. Voth, P. Salvador, J. J. Dannenberg, S. Dapprich, A. D. Daniels, Ö. Farkas, J. B. Foresman, J. V. Ortiz, J. Cioslowski and D. J. Fox, Gaussian 09 Revision E.01, 2009.

49 A. D. Becke, J. Chem. Phys., 1993, 98, 5648.

50 C. Lee, W. Yang and R. G. Parr, Phys. Rev. B, 1988, 37, 785-789.

51 S. Grimme, J. Antony, S. Ehrlich and H. Krieg, J. Chem. Phys., 2010, 132, 154104.

52 S. Grimme, S. Ehrlich and L. Goerigk, J. Comput. Chem., 2011, 32, 1456-1465.

53 T. H. Dunning Jr., J. Chem. Phys., 1989, 90, 1007-1023.

54 C. Adamo and V. Barone, J. Chem. Phys., 1999, 110, 6158-6170.

55 S. Grimme, J. Chem. Phys., 2006, 124, 034108.

56 C. Møller and M. S. Plesset, Phys. Rev., 1934, 46, 618-622.

57 J. Gauss and J. F. Stanton, Chem. Phys. Lett., 1997, 276, 70-77.

58 J. F. Stanton, J. Gauss, L. Cheng, M. E. Harding, D. A. Matthews and P. G. Szalay, CFOUR, Coupled-Cluster techniques for Computational Chemistry, a quantum-chemical program package, With contributions from A. A. Auer, R. J. Bartlett, U. Benedikt, C. Berger, D. E. Bernholdt, Y. J. Bomble, O. Christiansen, F. Engel, R. Faber, M. Heckert, O. Heun, M. Hilgenberg, C. Huber, T.-C. Jagau, D. Jonsson, J. Jusélius, T. Kirsch, K. Klein, W. J. Lauderdale, F. Lipparini, T. Metzroth, L. A. Mück, D. P. O’Neill, D. R. Price, E. Prochnow, C. Puzzarini, K. Ruud, F. Schiffmann, W. Schwalbach, C. Simmons, S. Stopkowicz, A. Tajti, J. Vázquez, F. Wang, J. D. Watts and the integral packages MOLECULE (J. Almlöf and P. R. Taylor), PROPS (P. R. Taylor), ABACUS (T. Helgaker, H. J. A. Jensen, P. Jørgensen, and J. Olsen), and ECP routines by A. V. Mitin and C. van Wüllen, for the current version, see http://www.cfour.de. 59 D. A. Matthews, L. Cheng, M. E. Harding, F. Lipparini, S. Stopkowicz, T.-C. Jagau, P. G. Szalay, J. Gauss and J. F. Stanton, J. Chem. Phys., 2020, 152, 214108.
60 P. Huber-Wälchli and H. H. Günthard, Spectrochim. Acta, Part A, 1981, 37, 285-304.

61 H. H. Nielsen, Rev. Mod. Phys., 1951, 23, 90-136.

62 We note that the hot band $\left(2 \nu_{6}-\nu_{6}\right)$ of trans- $\mathrm{HCOOH}$ in Chem. Sci., 2019, 10, 6285-6294 (ref. 24) was incorrectly assumed to be shifted by $x_{66}$ rather than $2 x_{66}$ from the $\nu_{6}$ fundamental. By considering the missing factor of two, the predicted shift of this non-isomeric hot band is similar to the cis-trans-shift of $\nu_{6}$, i.e., it could contribute to the band assigned to $\nu_{6}$ of cis-HCOOH. The expected intensity of the $\left(2 \nu_{6}-\nu_{6}\right)$ hot band, however, is distinctly too small for it to be the sole contribution to the band at $1093 \mathrm{~cm}^{-1}$. As such, the cis-HCOOH assignment remains largely unaffected.

63 W. H. Weber, P. D. Maker, J. Johns and E. Weinberger, J. Mol. Spectrosc., 1987, 121, 243-260.

64 O. I. Baskakov and J. Demaison, J. Mol. Spectrosc., 2002, 211, 262-272.

65 K. L. Goh, P. P. Ong and T. L. Tan, Spectrochim. Acta, Part A, 1999, 55, 2601-2614.

66 O. I. Baskakov, S. Alanko and M. Koivusaari, J. Mol. Spectrosc., 1999, 198, 40-42.

67 K. L. Goh, P. P. Ong, T. L. Tan, W. F. Wang and H. H. Teo, J. Mol. Spectrosc., 1998, 190, 125-129.

68 O. I. Baskakov, J. Lohilahti and V.-M. Horneman, J. Mol. Spectrosc., 2003, 219, 191-199.

69 R. A'dawiah, T. L. Tan and L. L. Ng, J. Mol. Spectrosc., 2018, 349, 43-48.

70 O. I. Baskakov, J. Mol. Spectrosc., 2002, 213, 1-7.

71 L. Nemes, A. R. W. McKellar and J. W. C. Johns, J. Opt. Soc. Am. B, 1987, 4, 1165-1172.

72 K. L. Goh, P. P. Ong, H. H. Teo and T. L. Tan, J. Mol. Spectrosc., 1999, 197, 322-323.

73 T. L. Tan, K. L. Goh, P. P. Ong and H. H. Teo, J. Mol. Spectrosc., 1999, 198, 110-114.

74 O. I. Baskakov, J. Mol. Spectrosc., 2001, 208, 194-196.

75 K. L. Goh, P. P. Ong, H. H. Teo and T. L. Tan, Spectrochim. Acta, Part A, 2000, 56, 991-1001.

76 T. L. Tan, K. L. Goh, P. P. Ong and H. H. Teo, J. Mol. Spectrosc., 1999, 195, 324-327.

77 D. Luckhaus, M. Quack and M. Willeke, Z. Phys. Chem., 2000, 214, 889.

78 D. A. Long, The Raman effect: A unified treatment of the theory of Raman scattering by molecules, Wiley, Chichester and New York, 2002.

79 S. J. Daunt and H. F. Shurvell, J. Mol. Spectrosc., 1976, 62, 373-395. 